\title{
Collection and Characterization of Ultra-Fine Airborne Particulates
}

\author{
J. J. Bang*, L. E. Murr**, and M. A. Chaney**
}

*Environmental Science \& Engineering Program, The University of Texas at El Paso, TX 79968

**Dept. of Metallurgical and Materials Engineering, The University of Texas at El Paso, $500 \mathrm{~S}$. University, M-201, El Paso, TX 79968.

The collection, quantification, and characterization of airborne ultra-fine and nanoparticulates have become an important issue in the context of human respiratory health because evidence is increasing that nanoparticles suspended in ambient air are particularly toxic and unusually ubiquitous [1-5]. In addition, ultra-fine airborne particulates are predominantly agglomerates of crystalline or microcrystalline nanoparticulates [6,7]. Such nanocrystalline agglomerates possess unusual shapes and extraordinary surface-to-volume ratios, rendering them particularly suited for promoting photocatalysis in the atmosphere and efficient attachment to deep lung tissue in the human body.

In this paper we describe the calibration and use of a thermal precipitation device for the efficient collection and analysis of atmospheric nanoparticles. The device employs a heated wire and a large ice water cooled copper substrate to create a thermal gradient driving airborne particulates onto $3 \mathrm{~mm}$ carbon/formvar-coated nickel grids for observation in the transmission electron microscope (TEM). Details of the thermal precipitator have been described elsewhere [8].

Figure 1 shows two examples of thermal-precipitator calibration utilizing burning paper smoke (Fig. 1(a)) and $\mathrm{Ag}$ nanoparticulates (Fig. 1(b)). Figure 2 illustrates the typical analysis of collected, airborne nanoparticulates in the TEM; utilizing selected-area electron diffraction (SAED) and energy-dispersive (X-ray) spectrometry (EDS) for quantitative (elemental) analysis. The analysis of more than 100 individual particulates similar to that illustrated in the sequence of Fig. 2 demonstrated that more than $87 \%$ were crystalline (nanocrystalline) aggregates. Of more than 200 particulates collected and analyzed by TEM in the El Paso, TX air over a 6-month period, more than $40 \%$ had aerodynamic diameters greater than $1 \mu \mathrm{m}$. Only $4 \%$ had aerodynamic diameters greater than $5 \mu \mathrm{m}[9]$.

\section{References}

[1] R. Churg et al., J. Environ. Med. 1 (1) (1999) 39.

[2] L. C. Renwick et al, Toxicol. Appl. Pharmacol. 172 (2) (2001) 119.

[3] Q. Zhiqiang et al., Atmos. Environ. 34 (2000) 443.

[4] M. Lundborg et al., Environ. Res. Sec. A. 86 (2001) 244.

[5] W. Moller et al., Toxi. \& Appl. Pharm. 182 (2002) 197.

[6] J. J. Bang and L. E. Murr, J. Mater. Sci. Letters 21 (2002) 361.

[7] J. J. Bang and L. E. Murr, JOM 54 (12) (2002) 28.

[8] J. J. Bang, E. A. Trillo, and L. E. Murr, J. Air \& Waste Managmt. Assoc., in press, 2003.

[9] This research was supported by a U.S. EPA grant through the Southwest Center for Environmental Research and Policy (SCERP: Project A-02-5), and an EPA Star Fellowship Award (Project U-91609601-0) to J. J. B. 

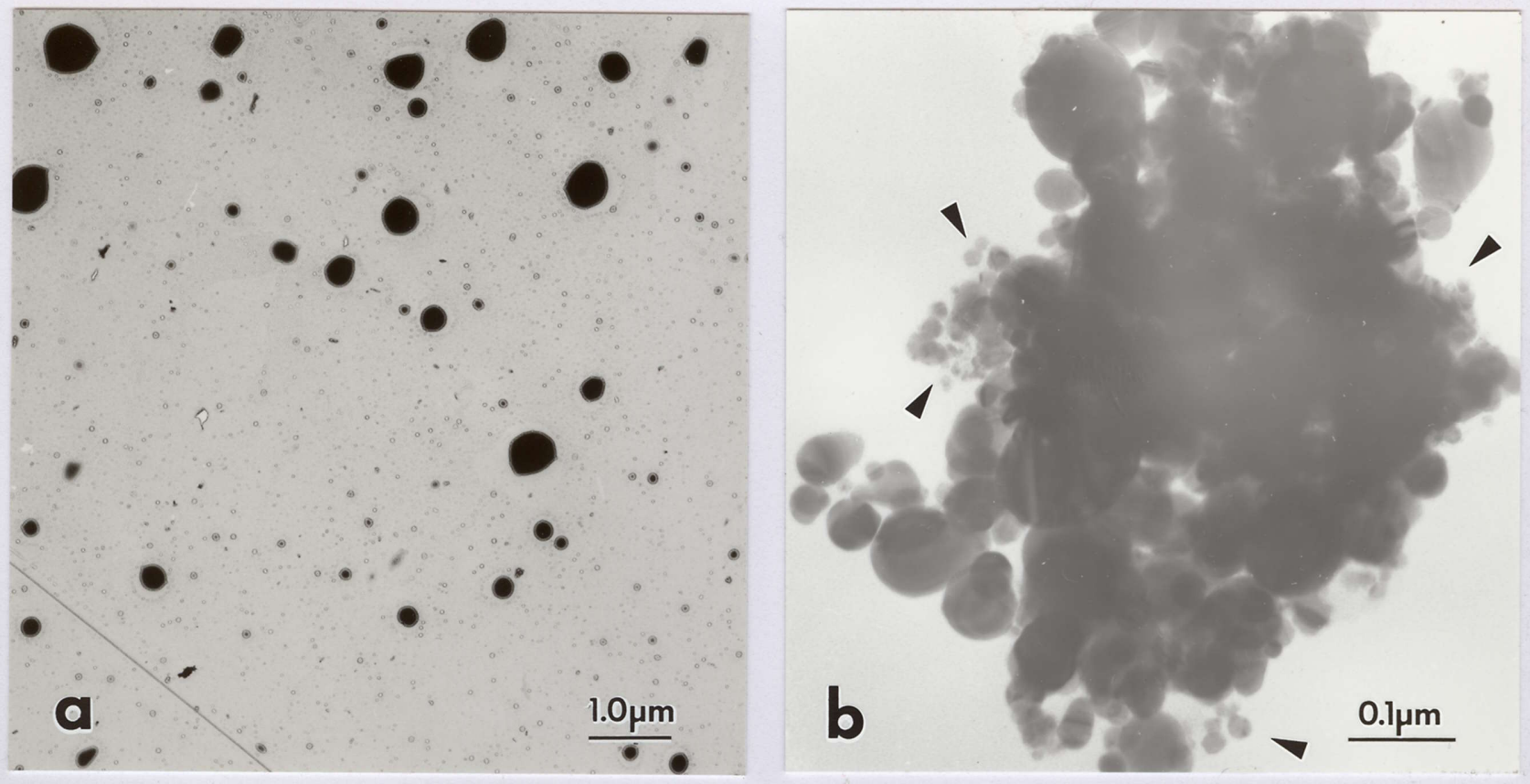

FIG. 1. Calibration of a thermophoretic precipitator. (a) Cigarette smoke particles ranging between $800 \mathrm{~nm}$ and $10 \mathrm{~nm}$ size are collected on a 3-mm formvar/carbon coated $\mathrm{Ni}$ grid. (b) Commercially available Ag nanoparticles are collected through the thermophoretic precipitator on a 3-mm formvar/carbon coated Ni grid. Particles with less than $10 \mathrm{~nm}$ in diameter are observed (arrows).
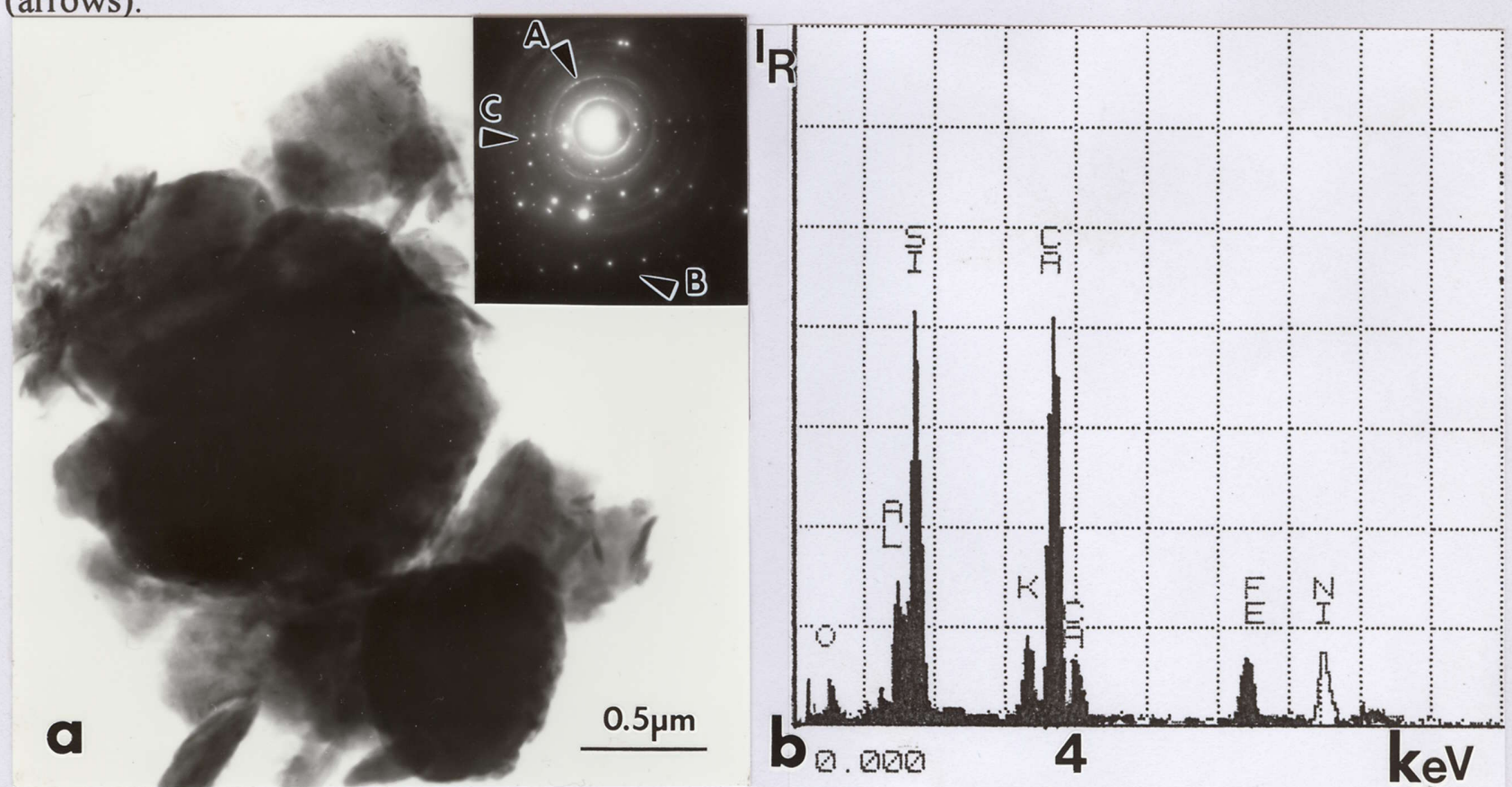

FIG. 2.

A typical example of ambient air particle aggregate collected by a thermophoretic precipitator. (a) A bright field image of an air particle is shown. The SAED pattern of the particle is insetted in the right upper corner. Three major species or crystalline components in the particle aggregate are detected by the three distinctive patterns including rings (A), spots at the bottom (B), and another spot pattern (C) on the left of the center. (b) An EDS shows elemental analysis of the aggregate particle. Ni peak is from the collection grid and acts as a calibration standard. 